\title{
Editorial
}

\section{Cuestionamiento a la doctrina neoliberal en los países subdesarrollados}

Según Smith, los hombres tienden a obrar de acuerdo a una fuerza natural, que es el egoísmo. Cada individuo que busca su beneficio privado contribuye al bien público, gracias a que el orden natural garantiza una armonía entre el interés público y el interés privado. De acuerdo a este postulado, la misión de la ciencia debe ser descubrir las leyes de ese orden natural y dejarle que se manifiesta libremente. De ahí la máxima liberal: "Laisser faire, laisser passer" (dejar hacer, dejar pasar), que, formulada como un dogma científico, sostiene que el mundo camina por sí mismo. Cualquier intento de intervenir sobre esta lógica natural sería perjudicial para el desarrollo económico y social de una nación.

De igual manera, Smith estableció las dos exigencias fundamentales para dejar que ese orden natural se manifestara: la competencia y la no-intervención del gobierno en el área económica, dejando que los sujetos económicos actúen libremente. En conclusión, el liberalismo clásico argumentó que el control económico ejercido por el gobiemo en el sistema mercantil es innecesario y, más aún, contraproducente.

En lo que respecta a la competencia, el liberalismo presupone en las sociedades modernas la existencia de una marco jurídico e institucional que tiene, a través del Estado, la única función de vigilar el cumplimiento de las reglas de juego de la supuesta economía social del mercado. De esta manera, se evitaría que los actores económicos exacerben los límites del egoísmo natural, garantizando que el beneficio privado contribuya efectivamente al bien común. En la 
práctica, la historia del capitalismo ha demostrado todo lo contrario. En las fases más avanzadas de su desarrollo se pasó a la formación de los monopolios y posteriormente de los oligopolios. Las consecuencias más dramáticas de esta nueva situación fueron la Primera y Segunda Guerras Mundiales.

El libre mercado quedó en las sociedades industrializadas como un mito de la economía, pues, en esta fase del capitalismo, esta nueva racionalidad económica se encargó de petrificar su significado social y ético. En su lugar, apareció un discurso político divorciado de la realidad concreta que, apoyándose en los más altos propósitos liberales, defendió la política expansionista de las principales potencias económicas, afectando drásticamente la división internacional del trabajo, donde, por supuesto, los países más afectados fueron los países agroexportadores.

A pesar de que en la actualidad estos planteamientos naturalistas son cuestionados científicamente por sostener una visión determinista de la realidad, la influencia de sus postulados teóricos, transformados a su vez en discursos políticos, siguen pesando en la sustentación de las políticas económicas de nuestros países y en diferente nivel, en la vida cotidiana de sus sociedades.

Los voceros oficiales de este modelo, embuídos de una concepción lineal de la realidad histórica, auguran para todas las naciones, pero especialmente para las más pobres, tiempos de bonanza económica y desarrollo humano. Estas profecías económicas siguen teniendo como núcleo central el paradigma del libre mercado. No obstante, sobre esta base se ha hecho algunos ajustes y se han agregado nuevos postulados teóricos. Por estas razones, a esta doctrina se le ha denominado "neoliberalismo". Sin embargo, y debido a la nueva racionalidad económica impulsada especialmente por el Fondo Monetario Intemacional y el Banco de Desarrollo, algunos autores han señalado que, debido a sus planteamientos y aplicaciones concretas en la actualidad, contradice con creces los contenidos teóricos del liberalismo propuesto por Adam Smith.

En lo que respecta a El Salvador, llama la atención que al margen de estos planteamientos liberales y neoliberales, todos los modelos económicos han tenido como característica principal la exacerbación del egoísmo de los diferentes actores económicos, al extremo, de que en función del interés privado y en detrimento del llamado bien común, se ha organizado el aparato estatal, produciendo como principal consecuencia, los niveles de pobreza, exclusión y marginación social que de todos es conocida.

En el marco de estos planteamientos economicistas, en la última década, los gobiemos de ARENA han organizado su política económica sustentándose en estos postulados teóricos. A partir de ellos, y en nombre de las expectativas nacionales, han rechazado sistemáticamente el manejo expansionista de las políticas monetarias y fiscales; han implementado los principios de la economía de 
la oferta, que promueve la reducción de los impuestos directos, con el fin de estimular la producción y ganancias de los grandes inversionistas privados. $\mathrm{Ha}$ promovido la privatización de las empresas públicas justificadas por la necesidad de reducir o eliminar los déficits fiscales, que son considerados los causantes de las presiones inflacionarias. Y, entre otras cosas, ha debilitado a los sindicatos, debido a que las medidas por las cuales luchan, a saber: incremento de salarios mínimos, contratos permarentes, protección contra los despidos, son consideradas distorsiones al mercado de trabajo.

Este modelo económico vigente, más allá de esta doctrina que lo sostiene, es en realidad una ideología que favorece al capitalismo de los oligopolios. Es un darwinismo social que cínicamente exacerba el egoísmo humano bajo diversas formas de competencia y en consecuencia, favorece a los que más tienen y aumenta las desigualdades económicas y el número de pobres en el mundo.

Esta constatación se hace más dramática en El Salvador, donde la debilidad institucional y la manipulación del Estado por los poderosos grupos con poder económico, han generado sostenidamente en el tiempo una crisis social y política con invalorables costos humanos y ecológicos.

La oposición radical a este paradigma denominado "neoliberalismo", más cercano - como ya lo expresamos- al darwinismo social, se justifica en términos de que su ideología profundamente individualista y socialmente antisolidaria está generando una crisis social global. Lo que tenemos a la vista está muy lejos de ser una economía social del mercado, por el contrario, es un sistema económico basado, entre otras cosas, en un excesivo individualismo; consumismo; énfasis en la competencia y despreocupación por los lazos de cooperación y solidaridad hacia todos los grupos y sectores sociales, pero, especialmente, hacia aquellos grupos y sectores sociales más vulnerables desde el punto de vista económico y social.

Por los resultados obtenidos y registrados en varios informes de organismos internacionales y nacionales, es indudable que los costos en razón de la vida humana y de su relación con el conjunto de ecosistemas no se pueden justificar bajo ningún punto de vista ético y científico. Irremediablemente un modelo económico gravitando alrededor de esta ideología condena a la sociedad a sul propia autodestrucción en términos sociales, económicos y políticos. Los altos índices de violencia y de contaminación, para enumerar algunos, son muestra clara de los efectos nocivos de la implementación de este modelo.

De lo anterior se deriva la importancia de crear y comprometerse con un nuevo enfoque teórico-práctico, sustentado sobre las bases de la madurez democrática, la educación, el fortalecimiento institucional a través de la concepción de un Estado con visión y políticas definidas a largo plazo. La economía moderna necesita estos requisitos para poder responder adecuadamente a las correcciones a que son sometidos continuamente los sistemas económicos. 
Sin haber logrado insertarnos efectivamente dentro de un modelo económico neoliberal, los ideólogos de este modelo tratan de convencer a la ciudadanía de sus ventajas. Los argumentos que intentan demostrar la panacea de sus beneficios se encuentran a la orden del día. El lenguaje - economicista-, basado en los supuestos teóricos de esta doctrina, se encarga de explicar los logros obtenidos en materia macroeconómica y apropiándose del discurso a favor de los pobres, promete que progresivamente se irá reduciendo su impacto social. No obstante, el neoliberalismo, como doctrina y como práctica, ha fallado en su intento de sacar a los países del Tercer Mundo de la pobreza; es más, en términos globales ha empeorado su situación.

Los resultados de su implementación demanda con urgencia reflexionar continuamente sobre esta realidad socioeconómica, política y cultural. Demostrar que bajo el paradigma de la mundialización económica nos estamos enrumbando hacia los que algunos estudios Ilaman la "dictadura del mercado". Estos hechos, bajo ningún concepto debe provocar en aquellos a los que en otros tiempos se les llamó "intelectuales orgánicos", el sentimiento de impotencia y escepticismo.

Ciertamente, la coyuntura geopolítica que gravita alrededor de la globalización y de la revolución tecnocrática ha llevado a varios de estos intelectuales a acomodarse a las circunstancias, a tolerar sin más las soluciones que nos vienen del exterior. Pero, por otra parte, también algunos científicos sociales han seguido trabajando, tratando de responder al siguiente gran desafío: lograr perfilar y construir una vía que nos permita un crecimiento equitativo, en armonía con la naturaleza, y en democracia, fundamentado en el desarrollo humano sostenible. 